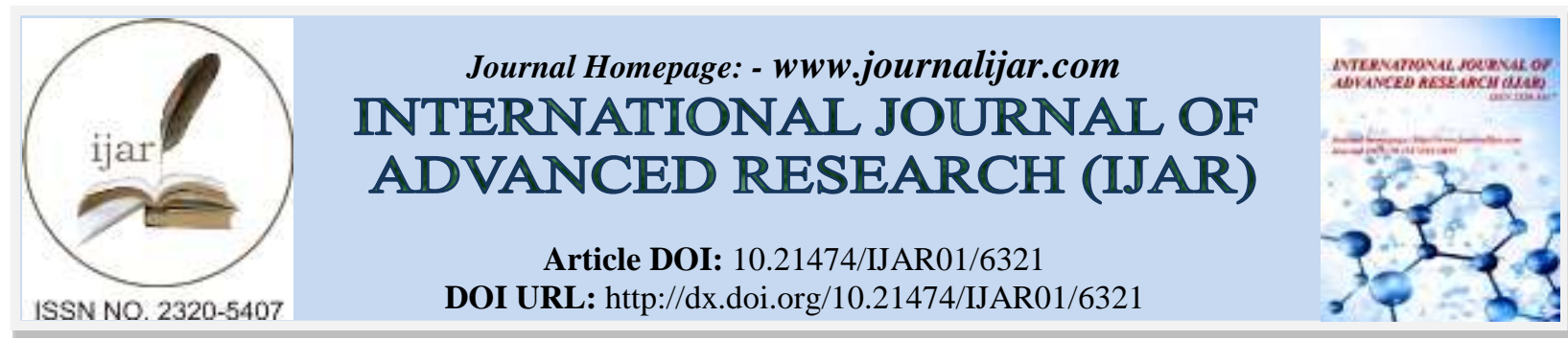

RESEARCH ARTICLE

\title{
PREVALENCE OF AND RISK FACTORS FOR DELAYED ONSET OF LACTATION IN SAUDI BREASTFEEDING WOMEN.
}

\section{Faisal Al-Husayni ${ }^{1}$, Mariann Al-Jehani ${ }^{1}$, Afnan Malibari ${ }^{1}$, Raghad Alawfi ${ }^{1}$, Shahad Sarhan ${ }^{1}$, Layan} Khushaim ${ }^{2}$, Bariah Drain ${ }^{2}$, Mansour Qurashi ${ }^{3}$, Loie Goronfolah ${ }^{4}$ and Mohammed Hasosah ${ }^{5}$.

1. College of Medicine, King Saud Bin Abdulaziz University for Health Sciences, National Guard Hospital, Jeddah, Saudi Arabia.

2. College of Medicine, Ibn Sina National College for Health Science, National Guard Hospital, Jeddah, Saudi Arabia.

3. Department of Neonatology, King Saud Bin Abdulaziz University for Health Sciences, National Guard Hospital, Jeddah, Saudi Arabia.

4. Department of Pediatric Allergy and Immunology, King Saud Bin Abdulaziz University for Health Sciences, National Guard Hospital, Jeddah, Saudi Arabia.

5. Department of Pediatric Gastroenterology, King Saud Bin Abdulaziz University for Health Sciences, National Guard Hospital, Jeddah, Saudi Arabia.

\section{Manuscript Info}

Manuscript History

Received: 16 November 2017

Final Accepted: 18 December 2017

Published: January 2018

Key words:-

Lactation; Breastfeeding; Delayed;

Questionnaire; Newborn.

\section{Abstract}

Background: Breastfeeding provides valuable benefits for both the mother and the baby. However, it may be delayed in some cases or not continued for the recommended duration.

Objectives: The aim of this study was to identify the prevalence of delayed onset of breastfeeding (more than 24 hours) in lactating women in the National Guard Hospital, Jeddah.

Methods: A brief, self-designed questionnaire that assessed the onset and duration of breastfeeding was administered via direct communication to 234 participants in the National Guard Hospital Jeddah, Saudi Arabia.

Results: We found that the prevalence of delayed breastfeeding in the studied sample was $73 \%$. Respondents who started breastfeeding after more than 24 hours had a significantly higher percentage of caesarean sections, complicated pregnancies, preterm deliveries, neonatal low birth weight, and difficulties in breastfeeding. Among the studied variables, the following were positively associated with the increased risk of starting breastfeeding after 24 hours in multivariable analyses: caesarean section $(\mathrm{OR}=7.8,95 \% \mathrm{CI}=2.9-20.9, \mathrm{P}<.0001)$, difficulties in breastfeeding ( $\mathrm{OR}=5.7,95 \% \mathrm{CI}=1.9-16.8, \mathrm{P}=0.002)$ and delivery time as in preterm deliveries $(\mathrm{OR}=2.3,95 \% \mathrm{CI}=0.8-6.3, \mathrm{P}=$ $0.119)$ and post term deliveries $(\mathrm{OR}=0.2,95 \mathrm{CI}=0.0-1.1, \mathrm{P}$-value $=$ 0.058 ) which cumulatively gives a $\mathrm{P}$-value $=0.027$.

Conclusion: Risk factors that increased significantly the likelihood of delayed initiation of breastfeeding included delivery by caesarean section, prematurity and difficulties in breastfeeding. Health education of women in the reproductive period should focus on the benefits of early breastfeeding to both the mother and the newborn.

Copy Right, IJAR, 2018,. All rights reserved. 


\section{Introduction:-}

Breastfeeding is a natural process by which a mother deepens connection with her baby. It is the first step that a baby needs towards a healthy early development (1). According to the United Nations Children's Emergency Fund (UNICEF), breastfeeding is recommended to be initiated within the first hour after delivery, to be exclusive for the first 6 months and to be continued, with complementary foods, for two years or beyond $(2,3)$. Unfortunately, only $40 \%$ of infants are exclusively breastfed for 6 months globally (4). In 2002, the National Immunization Survey conducted a study in the United States of America, which revealed that $71.4 \%$ of infants were breastfed, but only $13.3 \%$ were exclusively breastfed at 6 months of age (5). A slightly different situation was reported in Turkey, where $45.5 \%$ of infants had been breastfed within the first hour after birth (6). Reports from Saudi Arabia showed varying results regarding the initiation and the duration of breastfeeding (7-10). There are a lot of factors that are associated with the initiation and duration of breastfeeding. Inadequate milk and work-related problems of the mother were reported as the main reasons for stopping breastfeeding (7). Several factors, including parity, age of the mother and type of delivery, were found to be associated with the early initiation of breastfeeding (9). In addition, the mode of birth, planning of pregnancy, besides sex and maturity of the baby were related to the initiation of breastfeeding $(6,11)$. On the other hand, the act of exclusive breastfeeding was associated with the level of education, income, birth weight, type of delivery, employment status and nationality of the mother, in addition to her knowledge about the recommendations regarding the period of exclusive breastfeeding $(8,9)$. Apart from being the primary source of nutrients for the infant, breastfeeding had been associated with decreased mortality and morbidity rates and increased cognitive performance and educational achievement $(2,12,13)$. Breastfed infants had been found to have decreased incidence of diarrhea, respiratory infections, malocclusions, obesity and diabetes (13-16). Breastfeeding can be a natural birth control method. In addition, mothers who breastfeed their infants were found to have lower incidence of type 2 diabetes and invasive breast and ovarian cancers $(4,17)$.

Regarding the valuable benefits of breastfeeding for both the mother and the baby this study was conducted to identify the prevalence of delayed onset of breastfeeding (more than 24 hours) in lactating women in the National Guard Hospital - Jeddah, Saudi Arabia, also to look for factors affecting the initiation of breastfeeding, in order to eliminate them and hopefully increase the prevalence of breastfeeding in the future.

\section{Methods:-}

A cross-sectional descriptive study was carried out from December 2017 to January 2018 in the National Guard Hospital, Jeddah, Saudi Arabia. Inclusion criteria were mothers who delivered between December 2017 and January 2018 in the National Guard Hospital, Jeddah, Saudi Arabia. The exclusion criteria were the following; mothers of infants diagnosed with galactosemia, mothers infected with human immunodeficiency virus, mothers taking antiretroviral medications, mothers with active tuberculosis, mothers infected with human T-cell lymphotropic virus, mothers using illicit drugs, mothers on chemotherapy and mothers on radiation therapy. Sample size calculation was based on a previous study (18). The prevalence of delayed onset of breastfeeding was $30.3 \%$. It was necessary to recruit 226 participants to be $90 \%$ confident with $5 \%$ margin of error. Consecutive sampling technique was used to include all females who delivered between December, 2017 and January, 2018 in National Guard Hospital Jeddah, Saudi Arabia.

A self-designed questionnaire was developed and validated. After taking the permission and assuring their confidentiality, the participants were interviewed.

\section{Statistical Methods:-}

Data analysis was carried out using SPSS version 22. All numerical variables were checked for normality by Shapiro Wilk test. Normally distributed variables were expressed as means \pm standard deviation and differences between groups were tested by one way ANOVA test. Abnormally distributed variables were expressed as median and interquartile range (25th - 75 th percentile) and differences tested using Kruskal-Wallis test. Categorical variables were summarized as frequencies and percentages and association between variables was tested using Pearson's Chi square or Fisher-Freeman-Halton Exact Tests as appropriate. Forward, stepwise logistic regression analysis was carried out to identify factors that increase significantly the likelihood of delayed initiation of breastfeeding. A p-value of $<0.05$ was considered statistically significant.

\section{Ethical considerations:-}

The data were obtained voluntarily and anonymously. No names, contact numbers, or IDs were gathered from the study participants. The data were kept in a safe place and were not accessible to any party but to the research team. 
Participants were considered to have consented if they agreed to participate in the interview. All of the information collected was kept strictly confidential.

\section{Results:-}

In this study, 234 participants responded to the questionnaire. All the mothers initiated breastfeeding. Figure 1 illustrates that more than half the respondents (53.4\%) started breastfeeding within 4 to 24 hours after delivery; $20.1 \%$ after 1 to 3 hours; $12.8 \%$ within the first hour; while only $13.7 \%$ started after more than 24 hours. Table 1 shows the demographic data, gravidity and parity of the respondents. The age of the respondents ranged from 18 to 43 years, with a mean of $30 \pm 6$. The majority of respondents resided in big cities $(90.2 \%)$, had family income of 3,000-10,000 SAR (74.8\%), and were not employed (80.3\%). The respondents with university degree or above represented $41.5 \%$. The number of pregnancies of the respondents (gravidity) ranged from one to ten with a median of 3 (IQR =2,4). The number of deliveries (parity) ranged from one to nine with a median value of 2 (IQR = 1, 4). None of the respondents smoked. There was no statistically significant relationship between the demographic factors, gravidity, or parity and the time to start breastfeeding ( $\mathrm{p}>0.05)$. Table 2 demonstrates the medical history of the respondents. The majority ( $90.2 \%$ ) did not suffer from chronic diseases. The most frequent disease among the respondents was hypothyroidism (4.3\%), followed by asthma (3.4\%), then diabetes mellitus (DM) (2.1\%) and hypertension $(1.7 \%)$. There was no statistically significant association between the presence or types of chronic diseases and the time to start breastfeeding ( $p>0.05$ ). Table 3 summarizes the obstetric and breastfeeding history of the respondents. Half the newborns were females (50\%). There were 3 twins: two both male twins and one both female twins. More than half the deliveries were vaginal (59.8\%), and the pregnancies were not complicated (69.2\%). The most frequent complications included reduced fetal heart rate (13.2\%) and gestational DM (11.5\%). The gender of the newborn was not significantly associated with the time to start breastfeeding $(\mathrm{p}=0.109)$. Most the pregnancies reached full term $(65 \%)$ and the weight of newborn was normal $(84.2 \%)$. Only one fifth $(20.1 \%)$ of respondents had a family history of delayed breastfeeding for more than 3 days. Only 28 respondents $(12.0 \%)$ reported facing difficulties in breastfeeding; 14 had nipple pain and other 14 had insufficient amount of milk. When the three groups of respondents were compared, respondents who started breastfeeding after more than 24 hours had a significantly higher percentage of caesarean sections $(78.1 \% ; \mathrm{p}<0.001)$, complicated pregnancies $(50 \% ; \mathrm{p}=$ $0.003)$, gestational hypertension $(12.5 ; \mathrm{p}=0.043)$, pre-eclampsia $(9.4 \% ; \mathrm{p}=0.017)$, reduced fetal heart rate $(12.5 \%$; $\mathrm{p}=0.043)$, breach presentation $(12.5 \% ; \mathrm{p}=0.010)$, preterm deliveries $(28.1 \% ; \mathrm{p}=0.019)$, neonatal low birth weight $(28.1 ; \mathrm{p}=0.048)$, and difficulties in breastfeeding $(28.1 \% ; \mathrm{p}=0.023)$. There was no significant association between time of breastfeeding and the gender of newborn or family history of delayed lactation $(p=0.109$ and 0.598 respectively). Figure 2 demonstrates the time of breastfeeding following vaginal delivery or caesarean section. The mothers who delivered by cesarean section had a significantly higher percentage of delayed breastfeeding than those who delivered vaginally ( $26.6 \%$ versus $5 \%$ ). Also, mothers who delivered vaginally had a higher prevalence of early breastfeeding within the first hour $(20.7 \%$ versus $1.1 \%)$. Table 4 shows the risk factors of delayed breastfeeding. Mothers who delivered by caesarean section, before full term and had perceived difficulties in breastfeeding had an increased likelihood of starting breastfeeding after more than 24 hours (odds ratio $=7.8,2.3$, and 5.7). 


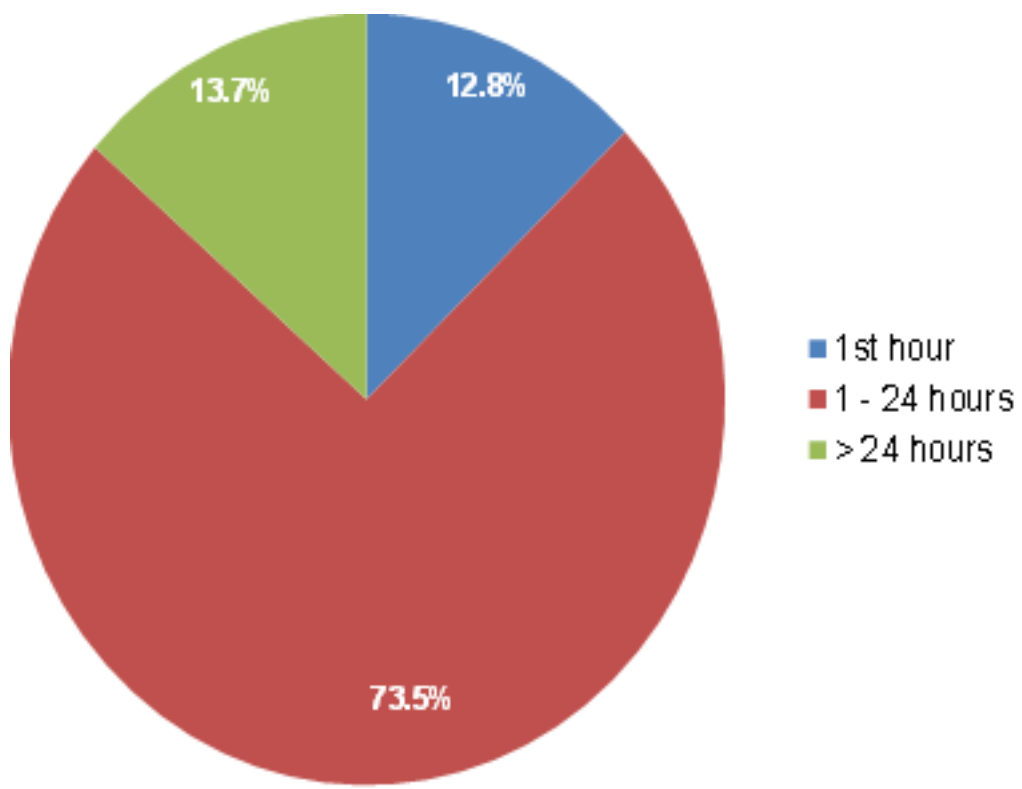

Figure 1:- Time to start breastfeeding after delivery in the respondents.

Table 1:- Demographic data of the respondents.

\begin{tabular}{|c|c|c|c|c|c|c|c|c|c|c|}
\hline & \multicolumn{8}{|c|}{ Respondents } & \multirow[t]{2}{*}{$\mathbf{P}$} \\
\hline & & \multicolumn{2}{|c|}{$\begin{array}{l}\text { Total } \\
(\mathrm{N}=234)\end{array}$} & \multicolumn{2}{|c|}{$\begin{array}{l}\text { 1st hour } \\
(\mathrm{N}=30)\end{array}$} & \multicolumn{2}{|c|}{$\begin{array}{l}1 \text { - } 24 \text { hours } \\
(\mathrm{N}=172)\end{array}$} & \multicolumn{2}{|c|}{$\begin{array}{l}>24 \text { hours } \\
(N=32)\end{array}$} & \\
\hline \multirow[t]{2}{*}{ Age (Years) } & Min-Max & \multicolumn{2}{|c|}{18 to 43} & \multicolumn{2}{|c|}{21 to 39} & \multicolumn{2}{|c|}{18 to 43} & \multicolumn{2}{|c|}{20 to 42} & 0.895 \\
\hline & Mean \pm SD & \multicolumn{2}{|c|}{$30 \pm 6$} & \multicolumn{2}{|c|}{$29 \pm 6$} & \multicolumn{2}{|c|}{$30 \pm 6$} & \multicolumn{2}{|c|}{$30 \pm 6$} & \\
\hline \multirow[t]{2}{*}{ City } & Big city & 211 & $90.2 \%$ & 28 & $93.3 \%$ & 155 & $90.1 \%$ & 28 & $87.5 \%$ & 0.770 \\
\hline & Rural city & 23 & $9.8 \%$ & 2 & $6.7 \%$ & 17 & $9.9 \%$ & 4 & $12.5 \%$ & \\
\hline \multirow{6}{*}{$\begin{array}{l}\text { Educational } \\
\text { Level }\end{array}$} & No certificate & 5 & $2.1 \%$ & 0 & $0.0 \%$ & 5 & $2.9 \%$ & 0 & $0.0 \%$ & 0.423 \\
\hline & Elementary & 18 & $7.7 \%$ & 0 & $0.0 \%$ & 17 & $9.9 \%$ & 1 & $3.1 \%$ & \\
\hline & Middle school & 24 & $10.3 \%$ & 5 & $16.7 \%$ & 16 & $9.3 \%$ & 3 & $9.4 \%$ & \\
\hline & High school & 81 & $34.6 \%$ & 10 & $33.3 \%$ & 62 & $36.0 \%$ & 9 & $28.1 \%$ & \\
\hline & Diploma & 9 & $3.8 \%$ & 2 & $6.7 \%$ & 6 & $3.5 \%$ & 1 & $3.1 \%$ & \\
\hline & $\begin{array}{ll}\begin{array}{l}\text { University } \\
\text { above }\end{array} & \& \\
\end{array}$ & 97 & $41.5 \%$ & 13 & $43.3 \%$ & 66 & $38.4 \%$ & 18 & $56.3 \%$ & \\
\hline \multirow{3}{*}{$\begin{array}{l}\text { Family } \\
\text { Income }\end{array}$} & $<3000$ SAR & 7 & $3.0 \%$ & 0 & $0.0 \%$ & 7 & $4.1 \%$ & 0 & $0.0 \%$ & 0.644 \\
\hline & $\begin{array}{l}\text { 3000-10000 } \\
\text { SAR }\end{array}$ & 175 & $74.8 \%$ & 25 & $83.3 \%$ & 124 & $72.1 \%$ & 26 & $81.3 \%$ & \\
\hline & $>10000 \mathrm{SAR}$ & 52 & $22.2 \%$ & 5 & $16.7 \%$ & 41 & $23.8 \%$ & 6 & $18.8 \%$ & \\
\hline \multirow[t]{3}{*}{ Occupation } & Employed & 22 & $9.4 \%$ & 3 & $10.0 \%$ & 18 & $10.5 \%$ & 1 & $3.1 \%$ & 0.217 \\
\hline & Not Employed & 188 & $80.3 \%$ & 21 & $70.0 \%$ & 140 & $81.4 \%$ & 27 & $84.4 \%$ & \\
\hline & Student & 24 & $10.3 \%$ & 6 & $20.0 \%$ & 14 & $8.1 \%$ & 4 & $12.5 \%$ & \\
\hline \multicolumn{2}{|c|}{$\begin{array}{ll}\text { Parity } & \text { Min-Max }\end{array}$} & \multicolumn{2}{|l|}{$1-9$} & \multicolumn{2}{|c|}{$1-6$} & \multicolumn{2}{|c|}{$1-8$} & \multicolumn{2}{|c|}{$1-9$} & 0.287 \\
\hline \multicolumn{2}{|c|}{ Median (IQR) } & \multicolumn{2}{|c|}{$2(1,4)$} & \multicolumn{2}{|c|}{$3(2,4)$} & \multicolumn{2}{|c|}{$2(1,4)$} & \multicolumn{2}{|c|}{$2(1,3)$} & \\
\hline \multicolumn{2}{|c|}{ Gravidity Min-Max } & \multirow{2}{*}{\multicolumn{2}{|c|}{$\frac{1-10}{3(2,4)}$}} & \multicolumn{2}{|c|}{$1-10$} & $1-1$ & & $1-$ & & 0.433 \\
\hline Median (IQI & & & & $4(2$ & & $3(1$, & & $3(1$ & & \\
\hline Smoking & No & 234 & $100.0 \%$ & 30 & $100.0 \%$ & 172 & $100.0 \%$ & 32 & $100.0 \%$ & \\
\hline
\end{tabular}

N: number; RAS: Riyal Saudi Arabia; Min: minimum; Max: maximum; SD: standard deviation; IQR: interquartile range. 
Table 2:- Medical history of the respondents.

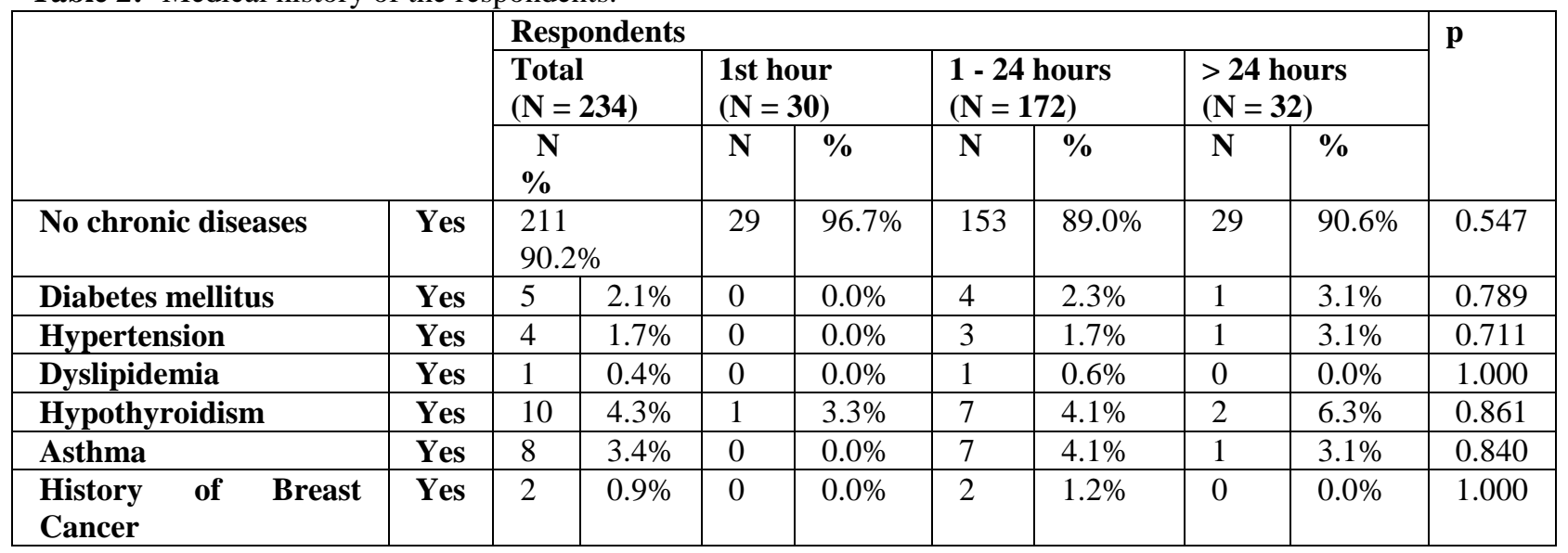

$\mathrm{N}$ : number

Table 3:- Obstetric and breastfeeding history of the respondents.

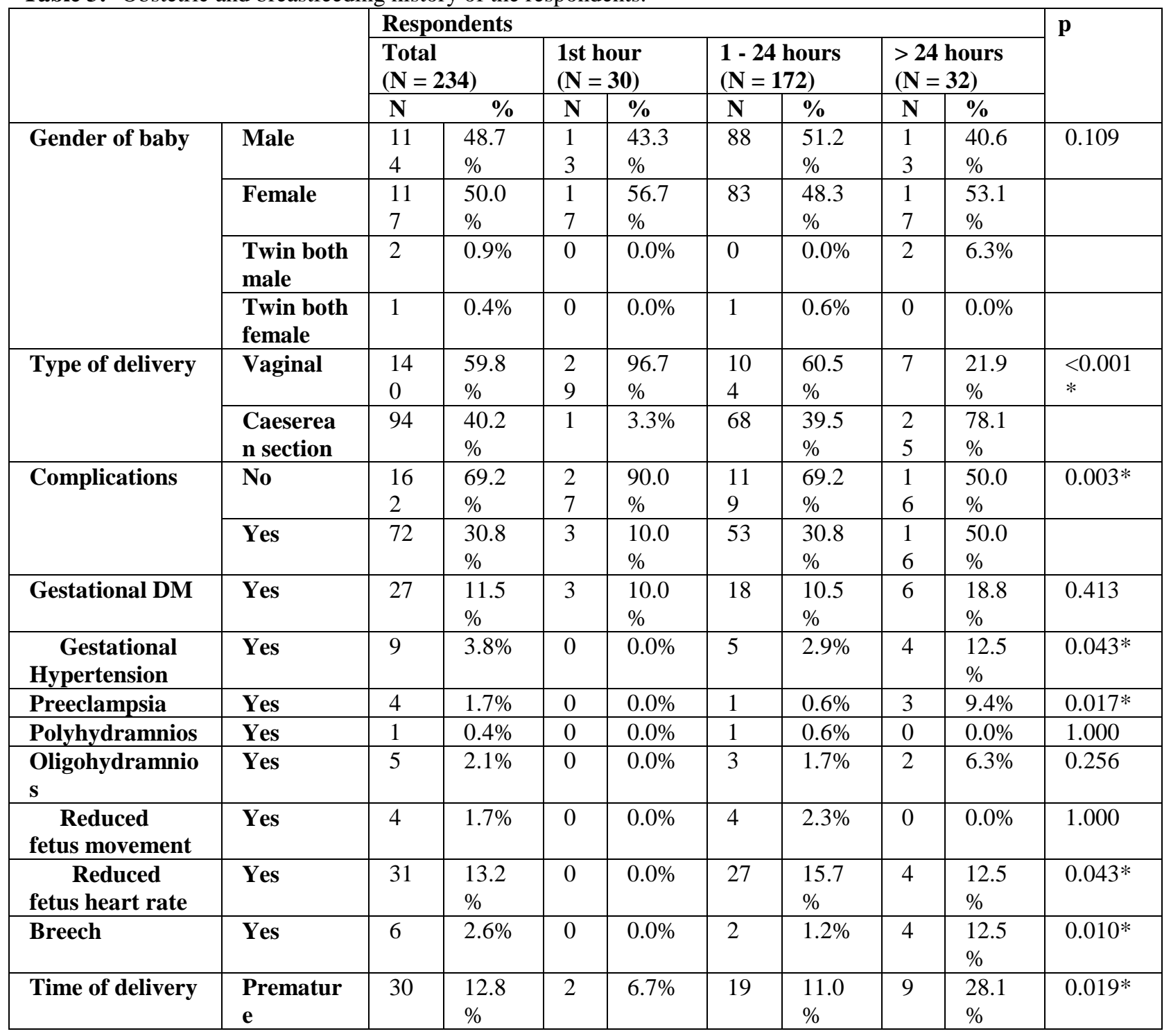




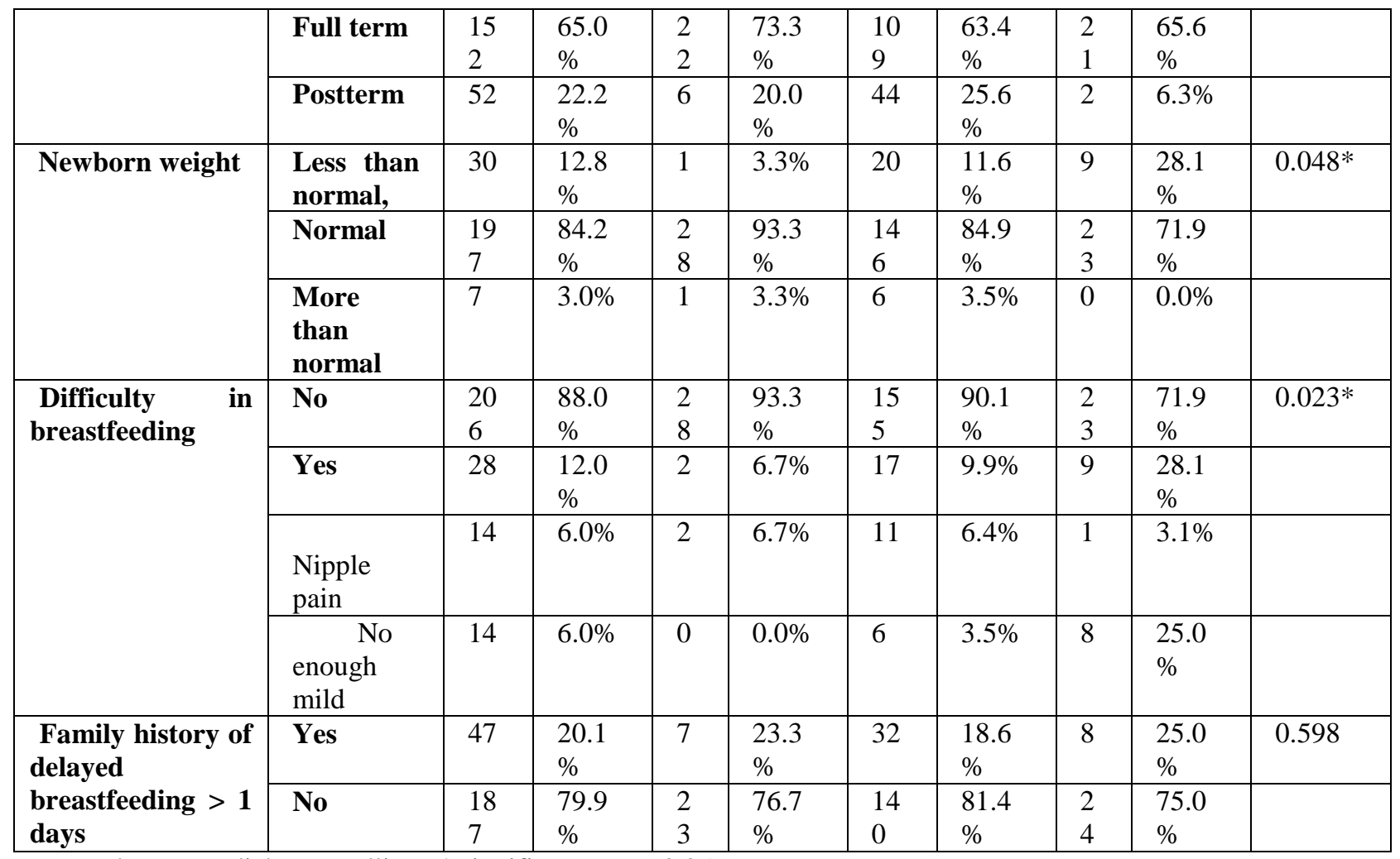

$\mathrm{N}$ : number; DM: diabetes mellitus; * significant at $\mathrm{p}<0.05$.

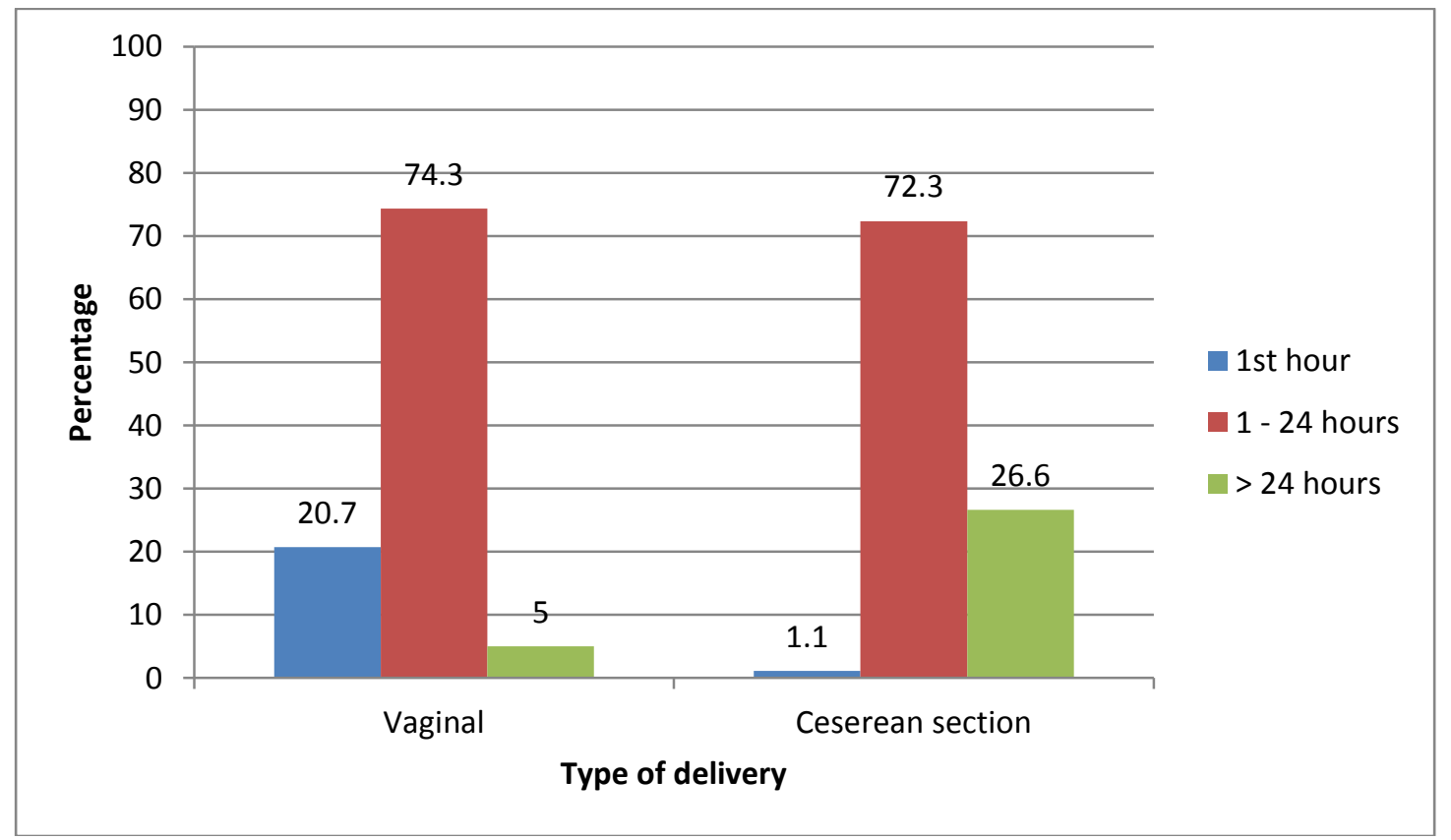

Figure 2:- The time of breastfeeding following vaginal or ceserean deliveries.

Table 4:- Forward stepwise logistic regression analysis to identify risk factors of delayed breastfeeding.

\begin{tabular}{|l|l|l|l|l|l|}
\hline \multicolumn{2}{|c|}{} & $\mathbf{p}$ & Odds ratio & \multicolumn{2}{|c|}{$\mathbf{9 5 \%}$ CI for odds ratio } \\
\cline { 4 - 6 } & & & Lower & Upper \\
\hline & Delivery type (caesarean section) & $<0.001^{*}$ & 7.8 & 2.9 & 20.9 \\
\cline { 2 - 6 } & Delivery time & $0.027^{*}$ & & & \\
\hline
\end{tabular}




\begin{tabular}{|c|l|l|l|l|l|}
\hline Preterm & 0.119 & 2.3 & 0.8 & 6.3 \\
\cline { 2 - 5 } & Post term & 0.058 & 0.2 & 0.0 & 1.1 \\
\cline { 2 - 5 } & Difficulties in breastfeeding (Yes) & $0.002^{*}$ & 5.7 & 1.9 & 16.8 \\
\cline { 2 - 5 } & Constant & $<0.001^{*}$ & 0.0 & & \\
\hline
\end{tabular}

CI: confidence interval; * significant at $\mathrm{p}<0.05$.

\section{Discussion:-}

Breastfeeding provides valuable health benefits for both the newborn and the mother (19). It is recommended that breastfeeding is initiated within the first hour after birth, to allow the newborn to benefit from colostrums, and to be maintained for 6 months without introduction of other food or milk formula (exclusive breastfeeding) (20). Many studies have evaluated the prevalence of exclusive breastfeeding in $\operatorname{KSA}(7,21,22)$. However, the time of initiation of breastfeeding and the risk factors for delay are still understudied. Therefore, the aim of this study was to identify the prevalence of delayed onset of lactation in lactating women in the National Guard Hospital - Jeddah. We found that the rate of breastfeeding was $100 \%$; that means all the women in the studied sample initiated breastfeeding at some time point after delivery. This finding agrees to other studies conducted in KSA and other countries. Al-Binali reported a prevalence of $100 \%$ among teachers and female health care workers in Abha (7, 23). Other Saudi Arabian studies have reported breastfeeding initiation rates ranging between 91.6 and 95\% (21, 24,25,26). Ninety-five per cent of mothers in Abu Dhabi reported starting breastfeeding after giving birth (27). In Kuwait, $92.5 \%$ of women have started breastfeeding by the time of hospital discharge (28). Similarly, the rate of breastfeeding was $96.1 \%$ in Athens, Greece (29). Lower rates of breastfeeding initiation were reported in other countries such as $87 \%$ in Boston, USA and $89 \%$ in Perth, Netherlands $(30,31)$. The higher rate of initiating breastfeeding in KSA may be explained by the tendency of Muslim communities to support and promote lactation based on the teachings of Islam (7). The American Academy of Pediatrics strongly recommends initiation of breastfeeding very soon after delivery. Early initiation of breastfeeding has been shown to help prevent early neonatal deaths (32). In the present study, only $12.8 \%$ started within the first hour. Nearly similar rates of initiation within one hour $(11.4 \%-13.2 \%)$ were reported in other regions of KSA by El-Gilany et al. and Amin et al. (33, 34). Higher rates of commencing breastfeeding, within the first hour after delivery, were also reported as follows: $23.2 \%$ in Jeddah (25); $31 \%$ in Abha (7); $39.0 \%$ in Kuwait (35); $18.3 \%$ in Lebanon (36); 43.7- 45.5\% in Turkey (6, 37); and 49.5\% in Jordan (38). In the current study, the prevalence of delayed breastfeeding was $13.7 \%$. Higher rates of delayed breastfeeding were reported. Al-Binali reported that $34.8 \%$ of the studied women in Abha, KSA (7), started only after 24 hours. Amin et al. found delayed initiation in $22.2 \%$ of studied mothers (34). Lower rates of delayed breastfeeding initiation were stated by Oweis et al. in Jordan (38). These differences between the various studies, as regards the rate of early or delayed initiation of breastfeeding, could be attributed to the cultural and educational variations between different communities; even in the same country. In some cultures, such as India and Thailand, colostrum is considered as something indigestible and unbeneficial; they express colostrum and discard it away, because they believe that if people step on it, it would lead to drying up of the mother's milk $(32,39)$. Also, some studies were conducted on women who were highly educated and working such as teachers and health care workers $(7,23)$; factors which may affect the pattern of breastfeeding and render the results inapplicable to other population. Women's prior knowledge of the benefits of giving colostrum in the first 3 days could result in better breastfeeding practices. Moreover, some countries, such as Jordan, have implemented policies in hospitals to promote early and exclusive breastfeeding (38). Hughes and Cox have stated that hospital policies play a significant role in promoting early initiation of breastfeeding (40). In this study, the most frequently reported difficulty with breastfeeding among the delayed initiators was insufficiency of breast milk. Amin et al. in Al-Ahsa, KSA, reported that the main reasons for late breastfeeding initiation were pain following delivery, inability to sit properly to breastfeed due to episiotomies, sedation, intake of drugs, weakness and fatigue, and no or low milk flow (34). The perceived insufficiency of breast milk is a risk factor also for cessation of lactation or dropping of exclusive breastfeeding (7). Perceived breast milk insufficiency has been associated with inadequate breastfeeding knowledge and technique by mothers, lack of maternal confidence in her breastfeeding ability promoted by infant crying behaviour or increased marketing and availability of commercial infant formula (41). Respondents in this study who started breastfeeding after more than 24 hours had a significantly higher percentage of complicated pregnancies (in the form of gestational hypertension, pre-eclampsia, reduced fetal heart rate, and breach presentation), preterm deliveries, neonatal low birth weight, and difficulties in breastfeeding. There was no significant association between the time of initiating breastfeeding and demographic factors, gravidity, parity, past medical history, family history of delayed feeding, or the gender of newborn. Similarly, other studies reported a lack of association between demographic factors and infant's gender $(28,42,43)$. In a systematic review of 18 research studies from Asia, Africa and South America, neither the age of the mother nor other factors such as 
family income or schooling were found to be independent risk factors preventing breastfeeding within the first hour of life (44). However, other studies have reported a significant association between increased maternal age (34), parity (34), the infant's gender (6) and initiation of breastfeeding within 24 hours post delivery. We found also that mothers who delivered by cesarean section had a significantly higher percentage of delayed breastfeeding than those who delivered vaginally (26.6\% versus $5 \%$ ). Also, mothers who delivered vaginally had a higher prevalence of early breastfeeding within the first hour (20.7\% versus $1.1 \%)$. This finding was observed also by several studies $(6,28$, $34,44,45,46)$. The rate of caesarean sections in our study (40.2\%) was much higher than that reported previously in KSA $(9.9-13 \%)(26,47)$. Not only that caesarean sections were associated with delayed initiation of breastfeeding, but they were reported to be significantly related to early cessation of breastfeeding and early introduction of other food or milk formula along the breast milk (25). Caesarean section delivery was also identified as a risk factor for not initiating breastfeeding (36). Infants delivered by caesarean section were found to start suckling later and administer bottle feeding more often during the first days of life (48). This association could be attributed to the effects of anaesthesia that may delay lactation, and/or post-surgical pain $(45,46)$. We identified caesarean section, prematurity and difficulties in breastfeeding as risk factors for starting breastfeeding after 24 hours. This finding agrees with previous studies $(42,49)$ which reported that breastfeeding initiation within the first 48 hours of childbirth was lower in women who gave birth by caesarean section, and had preterm or low birth weight infants.

\section{Conclusion:-}

Caesarean section delivery, prematurity and difficulties in breastfeeding are factors that increase significantly the risk of delayed initiation of breastfeeding. Health education of women in the reproductive period should focus on the benefits of early breastfeeding to both the mother and the newborn. The health values of colostrum should be emphasized, and any wrong beliefs should be properly addressed. Support should be available for women after caesarean section to encourage early initiation of breastfeeding. Implementing baby-friendly health policies and training of staff of maternity centers and hospitals can encourage early initiation and exclusive breastfeeding.

\section{Potential conflicts of interest:-}

The authors declare that there are no conflicts of interest.

Financial support:-

This study received no specific funding.

\section{Acknowledgements:-}

We would like to thank Ligaya Flores for her support and contribution in data collection.

\section{References:-}

1. Breastfeeding [Internet]. World Health Organization. 2017 [cited 30 December 2017]. Available from: http://www.who.int/topics/breastfeeding/en/

2. Breastfeeding [Internet]. UNICEF. 2017 [cited 30 December 2017]. Available from: https://www.unicef.org/nutrition/index_24824.html

3. Global Breastfeeding Collective [Internet]. World Health Organization. 2017 [cited 30 December 2017]. Available from: http://www.who.int/nutrition/topics/global-breastfeeding-collective/en/

4. 10 facts on breastfeeding [Internet]. World Health Organization. 2017 [cited 30 December 2017]. Available from: http://www.who.int/features/factfiles/breastfeeding/en/

5. Li R, Darling N, Maurice E, Barker L, Grummer-Strawn LM. Breastfeeding rates in the United States by characteristics of the child, mother, or family: the 2002 National Immunization Survey. Pediatrics. 2005;115(1):e31-7.

6. Yilmaz E, Yilmaz Z, Isik H, Gultekin IB, Timur H, Kara F, et al. Factors Associated with Breastfeeding Initiation and Exclusive Breastfeeding Rates in Turkish Adolescent Mothers. Breastfeeding medicine : the official journal of the Academy of Breastfeeding Medicine. 2016.

7. Al-Binali AM. Breastfeeding knowledge, attitude and practice among school teachers in Abha female educational district, southwestern Saudi Arabia. International breastfeeding journal. 2012;7(1):10.

8. Alzaheb RA. Factors Influencing Exclusive Breastfeeding in Tabuk, Saudi Arabia. Clinical medicine insights Pediatrics. 2017;11:1179556517698136. 
9. Amin T, Hablas H, Al Qader AA. Determinants of initiation and exclusivity of breastfeeding in Al Hassa, Saudi Arabia. Breastfeeding medicine : the official journal of the Academy of Breastfeeding Medicine. 2011;6(2):5968.

10. Shawky S, Abalkhail BA. Maternal factors associated with the duration of breastfeeding in Jeddah, Saudi Arabia. Paediatric and perinatal epidemiology. 2003;17(1):91-6.

11. Alzaheb RA. Factors associated with the initiation of breastfeeding within the first 48 hours of life in Tabuk, Saudi Arabia. International breastfeeding journal. 2016;11:21.

12. Sankar MJ, Sinha B, Chowdhury R, Bhandari N, Taneja S, Martines J, et al. Optimal breastfeeding practices and infant and child mortality: a systematic review and meta-analysis. Acta paediatrica (Oslo, Norway : 1992). 2015;104(467):3-13.

13. Victora CG, Bahl R, Barros AJ, Franca GV, Horton S, Krasevec J, et al. Breastfeeding in the 21st century: epidemiology, mechanisms, and lifelong effect. Lancet (London, England). 2016;387(10017):475-90.

14. Horta BL, Loret de Mola C, Victora CG. Long-term consequences of breastfeeding on cholesterol, obesity, systolic blood pressure and type 2 diabetes: a systematic review and meta-analysis. Acta paediatrica (Oslo, Norway : 1992). 2015;104(467):30-7.

15. Ip S, Chung M, Raman G, Chew P, Magula N, devine D, et al. Breastfeeding and maternal and infant health outcomes in developed countries. Evidence report/technology assessment. 2007(153):1-186.

16. 16. Peres KG, Cascaes AM, Nascimento GG, Victora CG. Effect of breastfeeding on malocclusions: a systematic review and meta-analysis. Acta paediatrica (Oslo, Norway : 1992). 2015;104(467):54-61.

17. Chowdhury R, Sinha B, Sankar MJ, Taneja S, Bhandari N, Rollins N, et al. Breastfeeding and maternal health outcomes: a systematic review and meta-analysis. Acta paediatrica (Oslo, Norway : 1992). 2015;104(467):96113.

18. Dewey KG, Nommsen-Rivers LA, Heinig MJ, Cohen RJ. Risk factors for suboptimal infant breastfeeding behavior, delayed onset of lactation, and excess neonatal weight loss. Pediatrics. 2003;112(3 Pt 1):607-19.

19. World Health Organization. Planning guide for national implementation of the Global Strategy for Infant and Young Child Feeding. Geneva: WHO; 2007.

20. World Health Organization. Report of the expert consultation of the optimal duration of exclusive breastfeeding. Geneva, Switzerland: World Health Organization, 2001 March 2001. Report 2011. Available from: http://www.who.int/mediacentre/news/statements/2011/breastfeeding_20110115/en/index.html.

21. Al-Hreashy FA, Tamim HM, Al-Baz N, Al-Kharji NH, Al-Amer A, Al-Ajmi H, et al. Patterns of breastfeeding practice during the first 6 months of life in Saudi Arabia. Saudi Med J. 2008;29(3):427-31.

22. Alwelaie YA, Alsuhaibani EA, Al-Harthy AM, Radwan RH, Al-Mohammady RG, Almutairi AM. Breastfeeding knowledge and attitude among Saudi women in Central Saudi Arabia. Saudi Med J. 2010;31(2):193-8.

23. Al-Binali AM. Knowledge, attitude and practice of Breast-Feeding among female health care workers in tertiary care hospitals. The Medical Journal of Cairo University. 2012;80(2).

24. El Mouzan MI, Al Omar AA, Al Salloum AA, Al Herbish AS, Qurachi MM. Trends in infant nutrition in Saudi Arabia: compliance with WHO recommendations. Annals of Saudi medicine. 2009;29(1):20.

25. Shawky S, Abalkhail BA. Maternal factors associated with the duration of breastfeeding in Jeddah, Saudi Arabia. Paediatric and perinatal epidemiology. 2003;17(1):91-6.

26. Al-Jassir MS, El-Bashir BM, Moizuddin SK. Surveillance of infant feeding practices in Riyadh city. Ann Saudi Med. 2004;24.

27. Gardner H, Green K, Gardner A. Infant feeding practices of Emirati women in the rapidly developing City of Abu Dhabi, United Arab Emirates. Int J Environ Res Public Health. 2015;12.

28. Dashti M, Scott J, Edwards CA, Al-Sughayer M. Determinants of breastfeeding initiation among mothers in Kuwait. International breastfeeding journal. 2010;5.

29. Pechlivani F, Vassilakou T, Sarafidou J, Zachou T, Anastasiou CA, Sidossis LS. Prevalence and determinants of exclusive breastfeeding during hospital stay in the area of Athens, Greece. Acta Paediatrica. 2005;94(7):92834.

30. Philipp BL, Malone KL, Cimo S, Merewood A. Sustained breastfeeding rates at a US baby-friendly hospital. Pediatrics. 2003;112(3):e234-e6.

31. Binns C, Gilchrist D, Gracey M, Zhang M, Scott J, Lee A. Factors associated with the initiation of breastfeeding by Aboriginal mothers in Perth. Public health nutrition. 2004;7(7):857.

32. Huffman SL, Zehner ER, Victora C. Can improvements in breast-feeding practices reduce neonatal mortality in developing countries? Midwifery. 2001;17(2):80-92. 
33. El-Gilany A, Shady E, Helal R. Exclusive breastfeeding in Al-Hassa, Saudi Arabia. Breastfeeding medicine : the official journal of the Academy of Breastfeeding Medicine. 2011;6.

34. Amin T, Hablas H, Al Qader AA. Determinants of initiation and exclusivity of breastfeeding in Al Hassa, Saudi Arabia. Breastfeeding medicine. 2011;6(2):59-68.

35. Al-Fadli H, Masoud GM, Al-Jasem L. Breast-feeding among Children Less than Two Years Old in Ahmadi Region, Kuwait. Kuwait Medical Journal. 2002;34(4):281-5.

36. Batal M, Boulghourjian C, Abdallah A, Afifi R. Breast-feeding and feeding practices of infants in a developing country: a national survey in Lebanon. Public Health Nutr. 2006;9.

37. Yanikkerem E, Tuncer R, Yilmaz K, Aslan M, Karadeniz G. Breast-feeding knowledge and practices among mothers in Manisa, Turkey. Midwifery. 2009;25(6):e19-e32.

38. 38. Oweis A, Tayem A, Froelicher ES. Breastfeeding practices among Jordanian women. Int J Nurs Pract. 2009;15.

39. Kaewsarn P, Moyle W, Creedy D. Thai nurses' beliefs about breastfeeding and postpartum practices. Journal of clinical nursing. 2003;12(4):467-75.

40. Hughes R, Cox S. An analysis of breastfeeding initiation in Tasmania by demographic and socioeconomic factors for the period 1981-1995. Breastfeeding review : professional publication of the Nursing Mothers' Association of Australia. 1999;7(2):19-23.

41. Segura-Millan S, Dewey KG, Perez-Escamilla R. Factors associated with perceived insufficient milk in a lowincome urban population in Mexico. J Nutr. 1994;124(2):202-12.

42. Alzaheb RA. Factors associated with the initiation of breastfeeding within the first 48 hours of life in Tabuk, Saudi Arabia. International breastfeeding journal. 2016;11:21.

43. Osman NA, el-Sabban FF. Infant-feeding practices in Al-Ain, United Arab Emirates. East Mediterr Health J. 1999;5.

44. Esteves TM, Daumas RP, Oliveira MI, Andrade CA, Leite IC. Factors associated to breastfeeding in the first hour of life: systematic review. Rev Saude Publica. 2014;48.

45. Albokhary AA, James JP. Does cesarean section have an impact on the successful initiation of breastfeeding in Saudi Arabia? Saudi Med J. 2014;35.

46. Dorgham L, Hafez S, Kamhawy H, Hassan W. Assessment of initiation of breastfeeding, prevalence of exclusive breastfeeding and their predictors in Taif, KSA. Life Sci J. 2014;11.

47. Chattopadhyay S, Sengupta P, Edrees Y, Lambourne A. Cesarean section; changing patterns in Saudi Arabia. International Journal of Gynecology \& Obstetrics. 1987;25(5):387-94.

48. Pérez-Escamilla R, Maulén-Radovan I, Dewey KG. The association between cesarean delivery and breastfeeding outcomes among Mexican women. American journal of public health. 1996;86(6):832-6.

49. El-Gilany AH, Sarraf B, Al-Wehady A. Factors associated with timely initiation of breastfeeding in Al-Hassa province, Saudi Arabia. East Mediterr Health J. 2012;18. 